\title{
Comparison of 3 Different Types of Spinal Arteriovenous Shunts below the Conus in Clinical Presentation, Radiologic Findings, and Outcomes
}

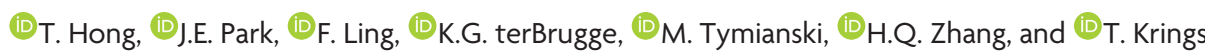

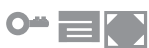

\begin{abstract}
BACKGROUND AND PURPOSE: Spinal arteriovenous shunts below the conus constitute 3 types of lesions, which have previously been mainly described in case reports, given their rarity, and are sometimes misdiagnosed. The purpose of this study was to describe the features of each type and compare these types as to epidemiologic features, clinical and radiologic presentations, treatment, and outcomes in a consecutive series of 48 cases.
\end{abstract}

MATERIALS AND METHODS: The prospectively collected data bases of 2 referral centers for spinal vascular lesions were retrospectively reviewed. Spinal arteriovenous shunts below the conus were defined as all dural and intradural shunts below the conus medullaris. Clinical features, radiologic findings, treatment results, and clinical outcomes were assessed.

RESULTS: There were filum terminale arteriovenous fistulas in 11 patients (22.9\%), radicular arteriovenous shunts in 7 patients (14.6\%), and spinal dural arteriovenous fistulas in 30 patients (62.5\%). Radicular arteriovenous shunts presented at a younger age $(P=.017)$ and with a higher incidence of back pain symptoms $(P=.037)$. A tethered spinal cord was found in $54.5 \%$ of patients with filum terminale arteriovenous fistulas and $23.3 \%$ of patients with spinal dural arteriovenous fistulas. After treatment, the angiographic complete obliteration rate was $89.4 \%$ and spinal function was improved significantly $(P<.001)$.

CONCLUSIONS: Three groups of spinal arteriovenous shunts below the conus can be differentiated according to clinical and radiologic features. Filum terminale arteriovenous fistulas are frequently associated with dysraphic malformations, which may suggest a particular embryologic origin.

ABBREVIATIONS: ALS = Aminoff-Logue scale; FTAVF $=$ filum terminale arteriovenous fistula; $r$ AVS $=$ radicular arteriovenous shunt; SDAVF $=$ spinal dural arteriovenous fistula

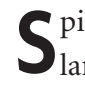
pinal arteriovenous lesions are rare and complex neurovascular diseases that can be categorized according to embryologic considerations, ${ }^{1}$ anatomic and imaging features, ${ }^{2}$ or their loca-

\footnotetext{
Received June 8, 2016; accepted after revision September 6.

From the Department of Neurosurgery (T.H., F.L., H.Q.Z.), Xuanwu Hospital, Capital Medical University, Beijing, China; Department of Radiology and Research Institute of Radiology (J.E.P.), Asan Medical Center, University of Ulsan College of Medicine, Seoul, Korea; and Department of Medical Imaging (K.G.T., T.K.) and Division of Neurosurgery (M.T.), Toronto Western Hospital, University of Toronto, Ontario, Canada.

Drs Krings and Zhang contributed equally to this work.

This work was supported by the National Natural Science Foundation of China $(81171165,81671202)$, the Beijing Municipal Administration of Hospital Clinical Medicine Development Project (ZY201309), and the Beijing Municipal Science and Technology Commission (D161100003816001).

Please address correspondence to Timo Krings, MD, PhD, Division of Neurosurgery, Department of Medical Imaging, Toronto Western Hospital, 399 Bathurst St, 3 McLaughling Wing, Toronto, Ontario M5T 2S8, Canada; e-mail Timo.Krings@uhn.ca

- Indicates open access to non-subscribers at www.ajnr.org

EIndicates article with supplemental on-line table.
}

tions. ${ }^{3}$ Among the spinal vascular malformations, arteriovenous shunts below the conus medullaris include some particular groups of lesions and are sometimes misdiagnosed due to similar clinical and radiologic presentations, which are worth addressing and differentiating separately. ${ }^{4}$ This group of lesions is distant from the spinal cord, ${ }^{5,6}$ presents mainly with progressive myelopathy rather than hemorrhage, and may be associated with dysraphic malformations, which suggest a unique embryologic origin. If diagnosis and angioarchitecture are correctly identified, treatment is relatively simple compared with spinal vascular lesions in other locations. ${ }^{7,8}$

According to their feeding arteries, we can classify 3 different types of spinal arteriovenous shunts below the conus: shunts fed by the artery of the filum terminale (filum terminale arteriovenous fistulas [FTAVFs]), shunts fed by dural branches (spinal dural arteriovenous fistulas [SDAVFs]), and shunts fed by radic-

Indicates article with supplemental on-line photos.

http://dx.doi.org/10.3174/ajnr.A5001

AJNR Am J Neuroradiol 38:403-09 Feb 2017 www.ajnr.org 
ular arteries (radicular arteriovenous shunts [rAVSs]). Previously, these types of vascular malformations have been described mainly in smaller case series or case reports. Since Djindjian et $\mathrm{al}^{9}$ reported the first case of FTAVF, several case reports ${ }^{10-13}$ and 2 patient series studies ${ }^{14,15}$ have been published. rAVSs that are located on a nerve root of the cauda equina have been reported in 2 cases to date. ${ }^{16}$ SDAVFs in this region can have lumbar or sacral segmental artery supply and constitute approximately $23 \%$ of the dural AVFs in larger series. ${ }^{17}$ Clinical and epidemiologic features, their relative proportion to each other, and the associated malformations of these 3 different shunts below the conus have not been described however, and the differential diagnoses of the 3 groups have not been investigated in greater detail, presumably given their rarity.

In this study, we review a series of 48 spinal arteriovenous shunts below the conus derived from the combined prospectively maintained data bases of 2 referral centers (Xuanwu Hospital, Beijing, China and Toronto Western Hospital, Toronto, Canada) and thus aim to compare epidemiologic features, clinical presentations, MR imaging and angiographic findings, treatment, and outcomes of 3 types of lesion at this location.

\section{MATERIALS AND METHODS}

\section{Patient Population and Clinical Evaluation}

We retrospectively reviewed patients from the combined prospectively maintained spinal vascular disease data bases (from January 2000 to August 2015) of 2 tertiary hospitals after having obtained local ethics board approval. Both institutions are referral centers for treating spinal vascular lesions and share similar protocols on diagnosis, treatment, and data base maintenance. We defined spinal arteriovenous shunts below the conus as all dural and intradural vascular lesions with the shunt occurring below the conus medullaris. For the SDAVF lesions, we selected those with fistula points on DSA located lower than the vertebral level of the conus, the latter was assessed by MR imaging in all screened patients. The clinical follow-up plan was 3, 12, 24, and 60 months after treatment, and angiographic follow-up was performed at 2-4 months after embolization or within 1 week after the surgical procedure to verify obliteration. Pretreatment and follow-up spinal functions were evaluated for gait, micturition, and defecation status according to the AminoffLogue scale (ALS) ${ }^{18}$; these evaluations were performed on the basis of the medical record by a clinician (T.H.) not directly involved in the care of these patients. We added a defecation subscale (On-line Table) due to frequent anal sphincter disturbance of lesions at the sacrum.

\section{Radiologic Evaluation}

Multisequence spinal MR images were available in all patients and were reviewed by an independent diagnostic neuroradiologist (J.E.P.), who was blinded to the clinical information of the patient. The evaluation included the presence of congestive edema, engorged veins, hemorrhage, and associated MR imaging findings (tethered spinal cord, lipoma, sacral cysts, or spina bifida). The radiologic definition of the tethered cord was the tip of the conus medullaris below the lower border of the L2 vertebral body. ${ }^{19}$

Standardized spinal DSA was performed, with evaluation of all segmental arteries including the bilateral internal iliac arteries and median sacral artery. Location of the shunt (dural, filum terminale, or along a nerve root of the cauda equina), angioarchitecture, and other associated vascular lesions were assessed. The angioarchitecture was evaluated regarding the number and type of the feeding arteries, the type of lesion (direct fistula versus intervening network or nidus), location of the lesion, and direction of venous drainage. Consensus diagnosis was made by the 2 senior authors (H.Q.Z. and T.K.).

\section{Treatment}

Treatment options included endovascular embolization, open surgery, or a combined approach. The decision to choose an open surgical versus an endovascular route was mainly based on the vascular anatomy and was done in a multidisciplinary conference. In general, the features of a tortuous course of the parent artery, a small caliber of the distal feeding artery, or a glomus-like architecture were considered unfavorable for an endovascular approach. Embolization was the first choice when the endovascular operator predicted that the arterial approach was available and an adequate safety margin to normal spinal feeding arteries was ensured. Only liquid embolic agents were used. Surgery was indicated when the embolization was not feasible or failed to achieve complete obliteration. The surgical approach varied according to lesion location and involved identification of the distal feeding artery and the proximal arterialized vein that was surgically disconnected to cure the shunt. Motor- and sphincter-evoked potential monitoring and indocyanine green video-angiography facilitated identification and safety during the surgical procedure.

\section{Statistical Analysis}

We performed mean age comparison with the ANOVA test and incidence comparison among different groups with the Fisher exact test. For the duration time data that deviated from a normal distribution, the Kruskal-Wallis test was applied. The Wilcoxon signed rank test was used to analyze the pre- and posttreatment ALS scores. Statistical significance was set at $P<.05$. All analyses were performed with SPSS software, Version 19.0.0 (IBM, Armonk, New York).

\section{RESULTS}

Forty-eight patients with spinal arteriovenous shunts below the conus were identified from the combined data bases that comprised a total of 359 spinal arteriovenous shunts (13.3\%). There were 36 males $(75 \%)$ and $12(25 \%)$ females with a mean age of 52.4 years (range, $5-81$ years). Mean clinical follow-up duration was 25.7 months (range, 3-77 months). Ten patients (20.8\%) were lost to follow-up after treatment.

\section{Angioarchitecture}

In our series, there were 11 patients $(22.9 \%)$ with FTAVFs, 7 patients (14.6\%) with rAVSs, and 30 patients (62.5\%) with SDAVFs (Table 1),

The FTAVFs $(n=11)$ were shown on angiograms as a direct communication of the filum terminale artery (distal continuation of the anterior spinal artery) and the filum terminale vein, which 
drained upward to the perimedullary veins (Fig 1 and On-line Fig 1). The origin of the anterior spinal artery feeding the artery of the filum terminale included the intercostal arteries $(n=4)$, lumbar arteries $(n=4)$, iliac arteries $(n=2)$, and the median sacral artery $(n=1)$. The fistula location ranged between the level of L2 and S2. FTAVFs with extra supply were found in 3 of the 11 patients (Fig $1 B$ ), and in 1 patient, an FTAVF was present together with a separate conus AVM (On-line Fig 1$)$.

The rAVSs $(n=7)$ were located on an intradural nerve root of the cauda equina between the radicular artery and a radicular vein draining to the perimedullary vein (Fig 2 and On-line Fig 2). The origin of the feeding artery was from the lateral sacral artery of the iliac artery in all 7 patients. The shunt presented as a direct fistula without an intervening network of abnormal arteries $(n=4)$ or as a micronidus-like structure with venous outpouching $(n=3)$. The shunt was located between L4 and S1 off the midline but intradurally (ie, on a nerve root). An rAVS was concomitant with a conus AVM in 3 of the 7 patients (Fig 2).

Table 1: Proportion of 3 types of spinal arteriovenous shunts below the conus

\begin{tabular}{lcc}
\hline \multicolumn{1}{c}{ Classification } & $\begin{array}{c}\text { No. of } \\
\text { Patients (\%) }\end{array}$ & Feeding Artery \\
\hline FTAVF & $11(22.9 \%)$ & Artery of the filum \\
FTAVF with extra supply & $3(6.2 \%)$ & terminale \\
FTAVF with conus AVM & $1(2.1 \%)$ & \\
rAVS & $7(14.6 \%)$ & Radicular artery of \\
rAVS with conus AVM & $3(6.3 \%)$ & the segmental artery \\
SDAVF & $30(62.5 \%)$ & Dural branch from the \\
& & lumbar artery or \\
& & lateral sacral artery \\
\hline
\end{tabular}
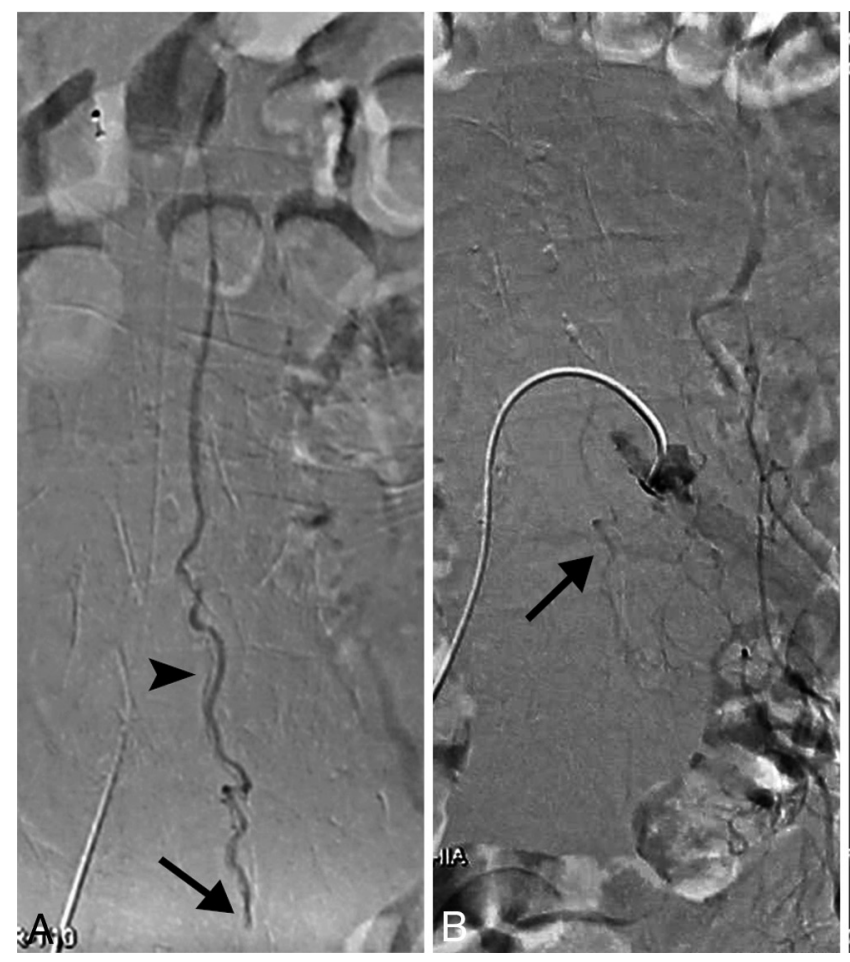

SDAVFs ( $n=30,62.5 \%$ ) constituted the largest group in our case series and were defined as fistulous communications between a radiculomeningeal artery and an intradural vein within the dura mater with retrograde drainage toward the perimedullary veins (Fig 3 and On-line Fig 3). The origin of the feeding artery included lumbar arteries in 9 patients and the lateral sacral artery of the iliac arteries in 21 patients. A single feeding artery was present in most patients $(n=27)$; in 2 patients, the shunt was fed by bilateral iliac arteries (On-line Fig 3); and in 1 patient, the shunt was fed by 2 adjacent lumbar segmental arteries. The location of the fistulas was between L2 and S2.

\section{Demographics, Clinical Presentation, and MR Imaging Findings}

Comparison of demographics, pretreatment clinical data, and MR imaging findings according to 3 different types of the lesions are summarized in Table 2 . The mean ages among patients with FTAVFs, rAVSs, and SDAVFs were significantly different $(P=$ .017). The post hoc analysis demonstrated that the patients with rAVSs were younger at presentation compared with those with FTAVFs (37.4 versus 52.9 years, $P=.032$ ) or SDAVFs (37.4 versus 55.6 years, $P=.005)$. All 3 groups showed a male predominance, though there was a nonsignificantly higher proportion of female $(42.9 \%)$ patients in the rAVS group compared with $27.3 \%$ in the FTAVF group and $20 \%$ in SDAVF group.

At the time of diagnosis, the symptoms of arteriovenous shunts below the conus were progressive paraparesis in 44 patients (91.7\%), bowel/bladder dysfunction in 38 patients (79.2\%), progressive hypesthesia in 33 patients $(68.8 \%)$, sensory numbness

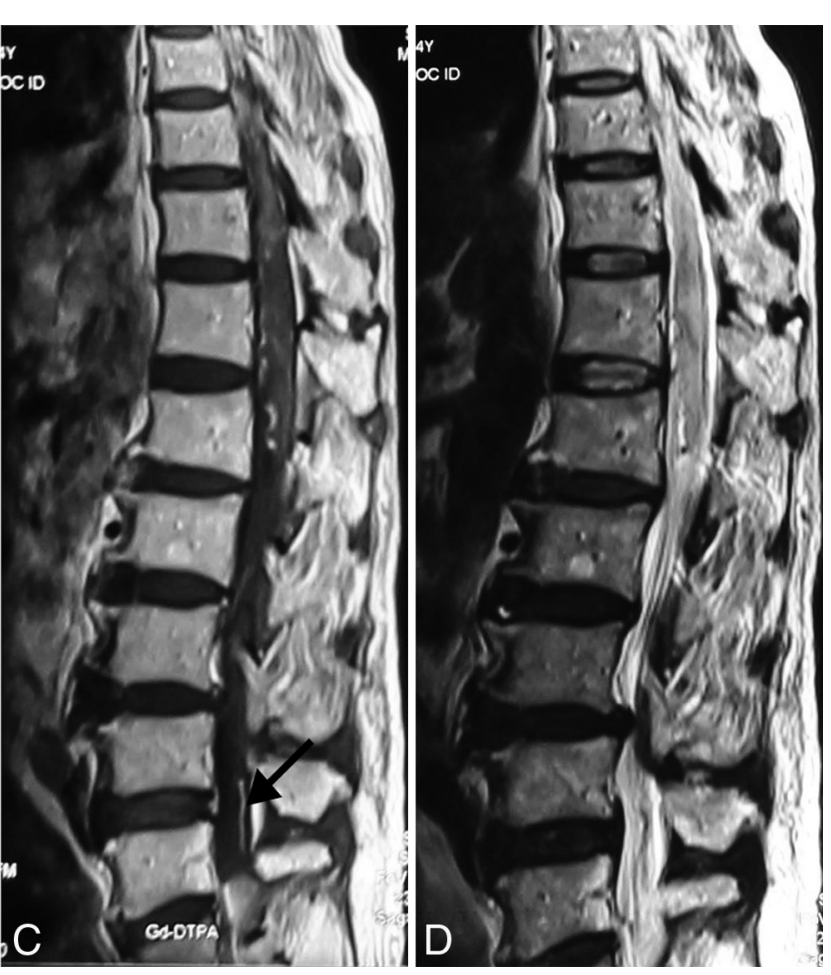

FIG 1. The radiologic presentation of a 64-year-old man with a FTAVF. A, Spinal angiogram shows the FTAVF at the level of S2 (arrow). Note the faint filum terminale artery (arrowhead) from the T10 intercostal artery, converging with the draining vein upwardly. B, Internal iliac artery angiogram demonstrates the extra supply of the FTAVF lesion in A. Note the same appearance of the drainage vein (arrow) as in $A$. C, The T1 contrast-enhanced image demonstrates the abnormally dilated and tortuous vessels situated on the surface of the spinal cord (arrow). $D$, T2-weighted image of the thoracic spine shows cord edema extending to the upper thoracic spinal cord. 

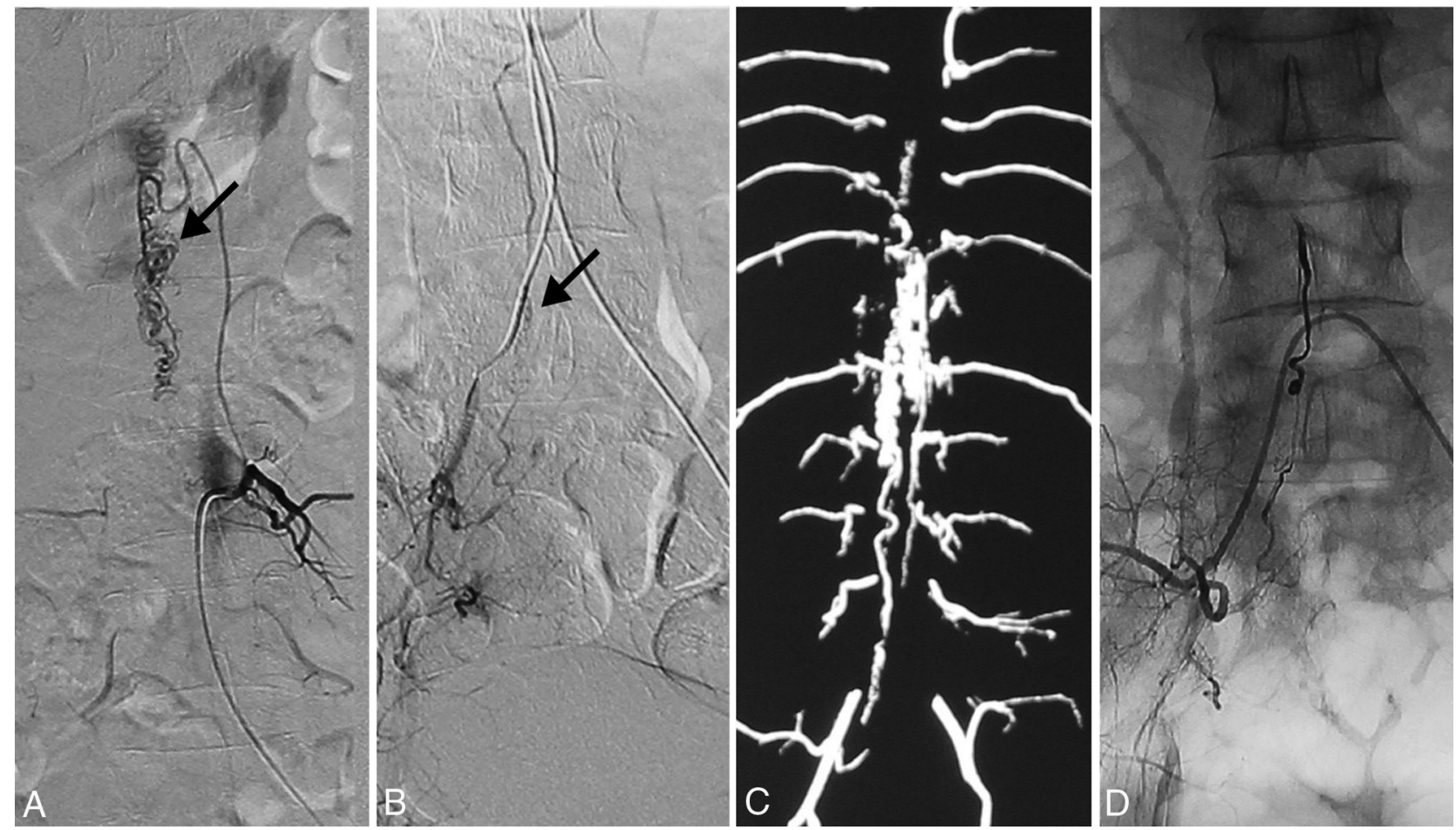

FIG 2. The radiologic presentation of a 34-year-old man with concomitant rAVS and conus AVM. A, Left L3 lumbar artery angiogram shows the nidus-type conus AVM at the level of L1 (arrow). B, Right internal iliac artery angiogram demonstrates an rAVS (arrow), which shares the draining vein of the AVM. C, Spinal CT angiography shows the draining vein of the rAVS and its connection to the conus AVM. D, Cast of liquid embolic agent with complete occlusion of the rAVS from the right internal iliac artery.
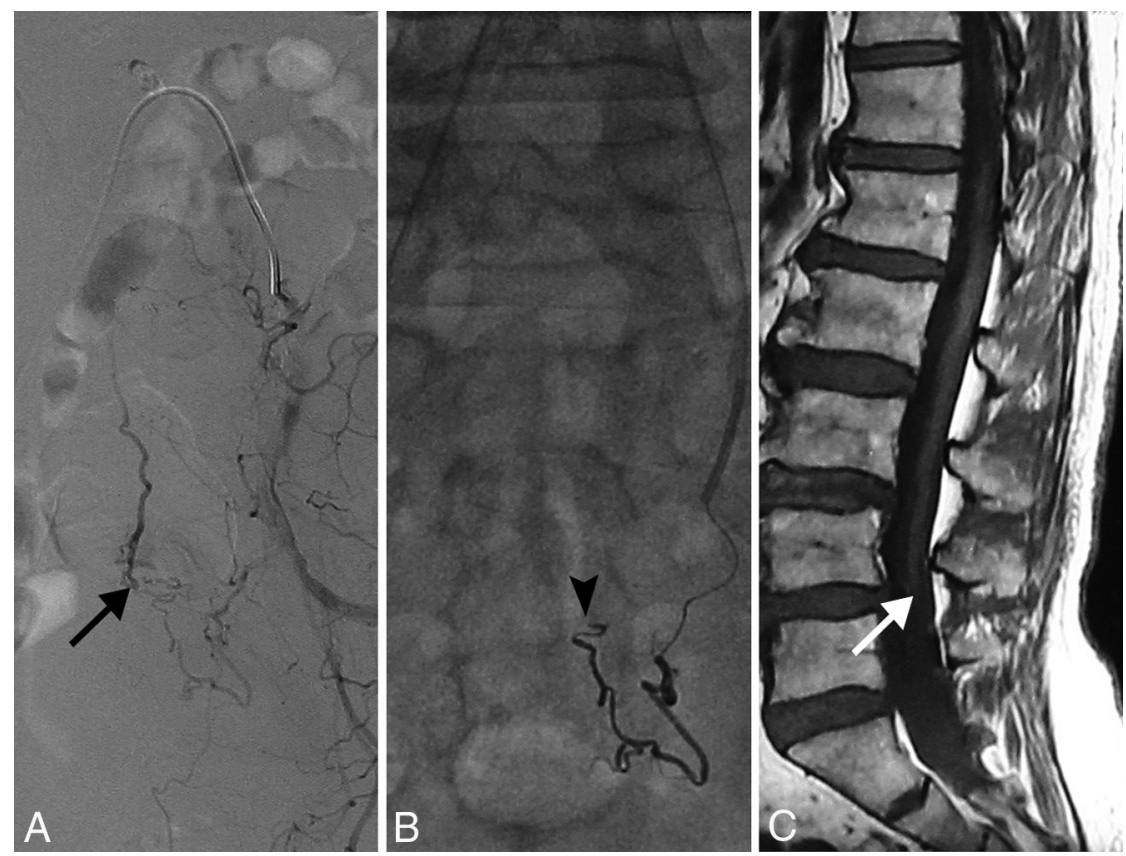

FIG 3. The radiologic presentation of a 64-year-old man with an SDAVF below the conus associated with a tethered cord. A, Left internal iliac artery angiogram shows the SDAVF at the level of S2 (arrow). B, Embolic material cast reveals that the embolic agent is approaching the proximal venous end (arrowhead). C, The patient also has a tethered cord (white arrow) on the Tl-weighted MR image.

in 24 patients $(50 \%)$, and back pain in 8 patients $(17.0 \%)$. The incidence of the symptoms among 3 different groups showed no statistical significance except for back pain. Three of 7 patients $(42.9 \%)$ had arteriovenous shunts with back pain, which was higher compared with those with SDAVFs $(P=.037$, multiple comparison analysis). The mean duration between the initial symptoms and diagnosis was 12.4 months (range, 10 days to 13.1 years). One patient with an rAVS presented with subarachnoid hemorrhage as verified by cranial CT and spinal MR imaging. None of the other lesions presented with hemorrhage. Delay of diagnosis due to initial misdiagnosis was recorded before admission and included lumbar degenerative diseases in 6 patients $(12.5 \%)$ and hypokalemia in 1 patient $(2.0 \%)$. Two patients had symptom deterioration after pulsed high-dose corticosteroid treatment.

On the MR imaging findings, 45 patients $(93.8 \%)$ had engorged perimedullary veins on T2-weighted or T1-weighted gadolinium-enhanced MR images and 44 patients $(91.7 \%)$ had spinal cord edema on the lower thoracic cord or conus medullaris. Both findings showed no obvious differences among the 3 groups. A tethered spinal cord was found in 6 $(54.5 \%)$ patients with FTAVF, in 7 (23.3\%) patients with SDAVF (Fig 3C), and in none of the patients with $\operatorname{rAVS}(P=.032)$. Ten patients had sacral lipomas on MR imaging, which included 7 lipomas of the filum terminale and 3 lipomeningoceles. Patients with FTAVF showed a higher inci- 
Table 2: Comparison of demographics, clinical presentation, and MRI findings of 3 types of spinal arteriovenous shunts below the conus $^{\mathrm{a}}$

\begin{tabular}{|c|c|c|c|c|c|}
\hline Characteristics & $\operatorname{FTAVF}(n=11)$ & $\operatorname{rAVS}(n=7)$ & $\operatorname{SDAVF}(n=30)$ & All $(n=48)$ & $P$ Value $^{\mathrm{b}}$ \\
\hline \multicolumn{6}{|l|}{ Demographic } \\
\hline Age (mean) (yr) & $52.9 \pm 12.6$ & $37.4 \pm 15.7$ & $55.6 \pm 14.9$ & $52.4 \pm 15.5$ & $.017^{c}$ \\
\hline Female sex & $3(27.3 \%)$ & $3(42.9 \%)$ & $6(20 \%)$ & $12(25 \%)$ & .443 \\
\hline \multicolumn{6}{|l|}{ Clinical symptoms } \\
\hline Duration of symptoms (mean) (mo) & $12.1 \pm 7.8$ & $9.9 \pm 9.8$ & $13.1 \pm 28.0$ & $12.4 \pm 22.6$ & .396 \\
\hline Back pain & $3(27.3 \%)$ & $3(42.9 \%)$ & $2(6.7 \%)$ & $8(17.0 \%)$ & $.028^{c}$ \\
\hline Progressive paraparesis & $11(100.0 \%)$ & $6(85.7 \%)$ & $27(90.0 \%)$ & $44(91.7 \%)$ & .598 \\
\hline Progressive hypesthesia & $7(63.6 \%)$ & $6(85.7 \%)$ & $20(66.7 \%)$ & $33(68.8 \%)$ & .739 \\
\hline Numbness & $5(45.5 \%)$ & $3(42.9 \%)$ & $16(53.3 \%)$ & $24(50 \%)$ & .844 \\
\hline Bowel/bladder dysfunction & $8(72.7 \%)$ & $4(57.1 \%)$ & $26(86.7 \%)$ & $38(79.2 \%)$ & .167 \\
\hline \multicolumn{6}{|l|}{ MRI findings } \\
\hline Spinal cord edema & $11(100 \%)$ & $5(71.4 \%)$ & $28(93.3 \%)$ & $44(91.7 \%)$ & .129 \\
\hline Engorged vein & $10(90.9 \%)$ & $6(85.7 \%)$ & $29(96.7 \%)$ & $45(93.8 \%)$ & .313 \\
\hline Spinal cord tethering & $6(54.5 \%)$ & $0(0.0 \%)$ & $7(23.3 \%)$ & $13(27.1 \%)$ & $.032^{c}$ \\
\hline Sacral lipoma & $5(45.5 \%)$ & $0(0.0 \%)$ & $5(16.7 \%)$ & $10(20.8 \%)$ & .061 \\
\hline
\end{tabular}

a Data are number and percentage unless otherwise indicated.

${ }^{\mathrm{b}}$ Comparison among FTAVF, rAVS, and SDAVF.

' Statistically significant values.

Table 3: Comparison of treatment and clinical outcomes of spinal arteriovenous shunts below the conus

\begin{tabular}{|c|c|c|c|c|c|}
\hline & FTAVF & rAVS & SDAVF & All & $P$ Value \\
\hline \multicolumn{6}{|l|}{ Treatment option (No.) } \\
\hline Embolization & 0 & 5 & 16 & 21 & $.002^{b}$ \\
\hline Surgery & 9 & 1 & 8 & 18 & \\
\hline$E+S$ & 2 & 1 & 6 & 9 & \\
\hline Mean FU & $24.0 \pm 26.1$ & $21.3 \pm 5.3$ & $27.6 \pm 20.6$ & $25.7 \pm 20.2$ & .54 \\
\hline Complete obliteration (No.) (\%) & 9 (100\%) & $6(100 \%)$ & 19 (82.6\%) & 34 (89.4\%) & .476 \\
\hline Median ALS grade pretreatment ${ }^{\mathrm{C}}$ & 9 & 7.5 & 7 & 7.5 & .273 \\
\hline Median ALS grade at last FU ${ }^{c}$ & 5 & 4 & 5 & 4.5 & \\
\hline$P$ value ${ }^{d}$ & $.023^{b}$ & .063 & $<.001^{\mathrm{b}}$ & $<.001^{\mathrm{b}}$ & \\
\hline
\end{tabular}

Note:-E+S indicates combined embolization-surgery; FU, follow-up.

${ }^{a}$ Comparison among FTAVF, rAVS, and SDAVF.

b Statistically significant values.

c Ten patients lost to follow-up after the treatments were excluded.

${ }^{\mathrm{d}}$ Comparison between pretreatment and last FU ALS grades.

dence of sacral lipoma ( 5 in 11, 45.5\%) compared with those with SDAVF (5 in 30, 16.7\%) and rAVS (0\%). Four patients with sacral cysts were noted, and 1 patient with an SDAVF had spina bifida.

\section{Treatment and Outcomes}

According to the therapeutic strategies, 21 (43.8\%) patients underwent embolization; 18 (37.5\%), surgery; and 9 (18.8\%), combined embolization and surgery due to failure to achieve complete obliteration by embolization (Table 3 ). The treatment patterns were different among the 3 groups $(P=.002)$. Of 11 patients with FTAVF, $9(81.8 \%)$ underwent surgery and 2 (18.2\%) underwent surgery after embolization failure, whereas patients with rAVS and SDAVF primarily underwent embolization $(71.4 \%$ and $53.3 \%$, respectively).

Of 38 patients with long-term clinical and angiographic follow-up data, angiographic complete obliteration was achieved in 34 patients $(89.4 \%)$. Embolization resulted in a complete obliteration rate of $56.0 \%$ ( 14 of 25), while surgery achieved a 100\% (21 of 21) cure. The median pretreatment ALS grade was 9 (range, 4-11) in patients with FTAVF, 7.5 (range, 0-10) in those with rAVS, and 7 (range, 0-11) in those with SDAVF, which showed a nonsignificant worse pretreatment function in patients with FTAVF. After treatment, the ALS grade showed significant improvement $(P<.001)$. According to the subgroups, the median ALS grade of patients with FTAVF at last follow-up was 5 com- pared with 9 before treatment $(P=.023), 4$ versus 7.5 in patients with $\operatorname{rAVS}(P=.063)$, and 5 versus 7 in those with SDAVF $(P<$ $.001)$.

\section{DISCUSSION}

To our knowledge, this is the first reported patient series focusing solely on spinal arteriovenous shunts below the conus. Given the consecutive inclusion and large series size, we were able to reveal the profile of each type and compare the clinical presentations, radiologic findings, and outcomes among FTAVF, rAVS, and SDAVF with statistical analysis.

\section{Comparison of Angioarchitecture}

The angioarchitecture of the 3 types of spinal arteriovenous lesions below the conus share some common features. Our study showed that most ${ }^{20}$ of these shunts were fistulous in nature, with nidus-type shunts being very rare and indicating rAVS if present. In addition, most shunts had a relatively slow flow and thus only mildly dilated arteries and veins. Furthermore, the venous drainage pattern was similar because in all shunts, the veins of the shunts drained upward to the perimedullary veins and thus caused venous congestion of the spinal cord. This drainage pattern explains that progressive myelopathy was the main symptom of all 3 types and hemorrhage occurred only rarely. In our series, 
it only occurred in 1 patient with an rAVS. Despite the above similarities, the 3 types of lesions have distinctive features to differentiate.

The filum terminale extends downward from the apex of the conus medullaris to the cul de sac of the dura at S2, so the FTAVF should be fed mainly by the filum terminale artery as the caudal continuation of the anterior spinal artery below the arcade of the cone. Whether the filum can have other blood supplies besides the filum terminale artery is still debatable ${ }^{13,14}$; as Djindjian et $\mathrm{al}^{5}$ reported, the coccygeal nerve with a radicular artery supply was adherent to the filum in its proximal portion. Thus, an explanation for FTAVFs localizing in the distal portion of the filum having an additional blood supply could be a radicular artery or dural artery, as shown in our series and in 1 previous case report. ${ }^{10}$ In some circumstances, a radicular artery may adhere to the distal portion of the filum and provide an extra vascular supply. The other possibility is a dural supply because the fistula localizes to the dural attachment point of the filum at around the S2 level, which then may include the dural arterial supply.

In our series, rAVSs were the type least often encountered, which is reflected by the literature because previously only 2 cases were reported. ${ }^{16}$ The arterial vascularization of the cauda equina nerve roots includes both distal and proximal radicular arteries with an anastomosis at the proximal one-third of the root. ${ }^{6}$ Ohtonari et $\mathrm{al}^{16}$ reported 2 cases of rAVSs fed by proximal radicular arteries, while in our study, all 7 rAVSs were fed by distal radicular arteries from segmental arteries. We believe that at least some of our cases may have also had proximal radicular artery feeders, which are suppressed by the main flow from their distal counterpart.

SDAVFs below the conus usually present with a single segmental feeding artery, which implies that the fistula is located within the dura directly adjacent to the nerve root (ie, where the radiculomeningeal artery pierces the dura). In cases in which the fistula is located between 2 adjacent nerve roots, dual segmental arterial supply from adjacent segmental arteries may be seen. This configuration was present in 3 patients in our series with SDAVFs supplied by 2 lumbar arteries or bilateral iliac arteries. During embolization, embolic agents should always approach the proximal venous end of the fistula to achieve complete obliteration, which may be more difficult to achieve with $\mathrm{N}$-butyl-cyanoacrylate (glue) in cases of dual supply because the glue will harden on contact with blood from the second feeder.

\section{Embryologic Consideration}

Development of the human spinal cord involves both primary and secondary neurulation. Unlike the primary neurulation, which establishes the brain and spinal cord and is derived from the ectoderm, all neural elements of secondary neurulation are developed from pluripotent mesodermal cells. These cells, termed the "caudal cell mass," coalesce and then epithelialize to form a separate neural tube that will connect with the neural tube formed by the primary neurulation. ${ }^{21,22}$ The exact level where the 2 neural tubes meet is still debatable, ranging from the upper conus ${ }^{23}$ to the lowest sacral level of the conus ${ }^{21}$; however, it is agreed that the caudal cell mass will give rise to the filum terminale and the cauda equina. Thus, the embryologic origin of FTAVFs and rAVSs be- low the conus is associated with secondary neurulation, differing from the remainder of intradural spinal vascular shunt origins that are associated with the primary neurulation. This may explain the interesting finding in our study that FTAVFs below the conus were often associated with spinal dysraphisms such as tethered cord, spinal lipoma, and spina bifida; this association was also shown in a previous case report. ${ }^{24}$ One may hypothesize that patients with abnormal secondary neurulation are more prone to develop abnormal vascular shunts: If during embryologic development, pluripotent cells at the caudal end of the human embryo were abnormally triggered to form a lipoma that will cause tethering, these abnormal pluripotent cells may also be prone to develop abnormal vascular shunts. ${ }^{25}$ The reason why SDAVFs were associated with dysraphisms may also be due to the abnormal pluripotent cells, which have a propensity to develop this acquired vascular lesion. However, why rAVSs were not associated with spinal dysraphisms in this series remains unclear.

The interesting finding that some patients demonstrated coexistence of rAVS with a conus AVM is presumably related to a low spinal arteriovenous metameric syndrome. We hypothesize that similar to thoracic, cervical, and cerebral metameric syndromes, abnormal cells that are prone to form arteriovenous shunts migrated along their segment and seeded daughter cells along their migrational path as previously described in cerebral arteriovenous metameric syndromes (Wyburn-Mason syndrome). ${ }^{26}$

\section{Differential Diagnosis and Treatment}

Spinal arteriovenous shunts below the conus may not be as rare as was previously thought because they represented $13.3 \%$ of all spinal shunts in our data base. However, misdiagnosis is not uncommon according to the similar clinical manifestation and nonspecific radiologic findings among the different groups. Our study suggests some differential diagnostic clues. rAVSs show a younger age at first presentation, a larger female proportion, and a higher incidence of pain symptoms and hemorrhage. FTAVFs and SDAVFs share a similar age at onset, which may be related to the same pathophysiology of venous hypertension. However, FTAVFs present with a different feeding artery derived from the anterior spinal artery and they are more commonly associated with dysraphic malformations. A standard spinal angiography, including the bilateral internal iliac arteries and median sacral artery, is the criterion standard to diagnose a lesion in this region. Treatment outcomes are better compared with spinal vascular lesions in other regions. Although embolization resulted in only a $56.0 \%$ complete obliteration rate in our series (given the often tortuous vascular anatomy and small caliber of the feeding arteries), surgical resection achieved $100 \%$ cure because disconnection of the venous outflow could be easily achieved after accurate intraoperative identification of the draining vein.

\section{Limitations}

Our study has some limitations pertaining to its retrospective design and sample volume. Due to the rarity of the disease and the potential of referral basis, our data may not represent the situation in the general population. Because some statistical comparisons are based on small numbers, there is the possibility of spurious statistically significant associations. Additionally, some cases were 
associated with additional abnormalities (ie, conus AVMs or spinal dysraphic disorders); thus, patient symptomatology may be related to various sources.

\section{CONCLUSIONS}

Our study reveals the differences in 3 types of spinal arteriovenous shunts below the conus. rAVSs have a younger age of onset and a higher incidence of pain symptoms and hemorrhage. FTAVFs are more commonly associated with dysraphic malformations. If diagnosed correctly, the treatment outcomes are better compared with spinal vascular lesions in other regions.

Disclosures: Tao Hong-RELATED: Grant: government granting agencies, Comments: National Natural Science Foundation of China (81171165, 81671202), Beijing Municipal Administration of Hospital Clinical Medicine Development Project (ZY201309), and Beijing Municipal Science and Technology Commission (D161100003816001). * *Money paid to the institution.

\section{REFERENCES}

1. Rodesch G, Hurth M, Alvarez H, et al. Angio-architecture of spinal cord arteriovenous shunts at presentation: clinical correlations in adults and children - the Bicêtre experience on 155 consecutive patients seen between 1981-1999. Acta Neurochir (Wien) 2004;146: 217-26; discussion 217-226 CrossRef Medline

2. Krings T. Vascular malformations of the spine and spinal cord*: anatomy, classification, treatment. Clin Neuroradiol 2010;20:5-24 CrossRef Medline

3. Spetzler RF, Detwiler PW, Riina HA, et al. Modified classification of spinal cord vascular lesions. J Neurosurg 2002;96:145-56 Medline

4. Lasjaunias P. Spinal cord vascular lesions. J Neurosurg 2003;98(1 suppl):117-19; author reply 119-20

5. Djindjian M, Ribeiro A, Ortega E, et al. The normal vascularization of the intradural filum terminale in man. Surg Radiol Anat 1988;10: 201-09 CrossRef Medline

6. Parke WW, Gammell K, Rothman RH. Arterial vascularization of the cauda equina. J Bone Joint Surg Am 1981;63:53-62 Medline

7. Trinh VT, Duckworth EA. Surgical excision of filum terminale arteriovenous fistulae after lumbar fusion: value of indocyanine green and theory on origins (a technical note and report of two cases). Surg Neurol Int 2011;2:63 CrossRef Medline

8. Takami T, Yamagata T, Mitsuhashi Y, et al. Direct surgery for spinal arteriovenous fistulas of the filum terminale with intraoperative image guidance. Spine (Phila Pa 1976) 2012;37:E1524-28 CrossRef Medline

9. Djindjian M, Djindjian R, Rey A, et al. Intradural extramedullary spinal arterio-venous malformations fed by the anterior spinal artery. Surg Neurol 1977;8:85-93 Medline
10. Jin YJ, Kim KJ, Kwon OK, et al. Perimedullary arteriovenous fistula of the filum terminale: case report. Neurosurgery 2010;66:E219-20; discussion E220 CrossRef Medline

11. Djindjian M, Ayache $P$, Brugieres $P$, et al. Sacral lipoma of the filum terminale with dural arteriovenous fistula: case report. J Neurosurg 1989;71:768-71 CrossRef Medline

12. Fischer S, Aguilar Perez M, Bassiouni H, et al. Arteriovenous fistula of the filum terminale: diagnosis, treatment, and literature review. Clin Neuroradiol 2013;23:309-14 CrossRef Medline

13. Hsu SW, Rodesch G, Luo CB, et al. Concomitant conus medullaris arteriovenous malformation and sacral dural arteriovenous fistula of the filum terminale. Interv Neuroradiol 2002;8:47-53 Medline

14. Lim SM, Choi IS, David CA. Spinal arteriovenous fistulas of the filum terminale. AJNR Am J Neuroradiol 2011;32:1846-50 CrossRef Medline

15. Chanthanaphak E, Pongpech S, Jiarakongmun P, et al. Filum terminale arteriovenous fistulas: the role of endovascular treatment. J Neurosurg Spine 2013;19:49-56 CrossRef Medline

16. Ohtonari T, Ota S, Nishihara N, et al. Arteriovenous fistula in a nerve root of the cauda equina fed by a proximal radiculo-medullary artery: a report of two cases. Interv Neuroradiol 2011;17:217-23 Medline

17. Saladino A, Atkinson JL, Rabinstein AA, et al. Surgical treatment of spinal dural arteriovenous fistulae: a consecutive series of 154 patients. Neurosurgery 2010;67:1350-57; discussion 1357-1358 CrossRef Medline

18. Aminoff MJ, Logue $V$. The prognosis of patients with spinal vascular malformations. Brain 1974;97:211-18 CrossRef Medline

19. Pang D, Wilberger JE Jr. Tethered cord syndrome in adults. J Neurosurg 1982;57:32-47 CrossRef Medline

20. Troude L Jr, Melot A, Brunel H, et al. Arteriovenous malformation of the filum terminale: an exceptional case. J Neurosurg 2016;124: 1712-15 CrossRef Medline

21. Sadler TW. Embryology of neural tube development. Am J Med Genet C Semin Med Genet 2005;135C:2-8 CrossRef Medline

22. Saitsu H, Yamada S, Uwabe C, et al. Development of the posterior neural tube in human embryos. Anat Embryol (Berl) 2004;209: 107-17 Medline

23. Hertzler DA 2nd, DePowell JJ, Stevenson CB, et al. Tethered cord syndrome: a review of the literature from embryology to adult presentation. Neurosurg Focus 2010;29:E1 CrossRef Medline

24. Krisht KM, Karsy M, Ray WZ, et al. Extraspinal type I dural arteriovenous fistula with a lumbosacral lipomyelomeningocele: a case report and review of the literature. Case Rep Neurol Med 2015;2015: 526321 CrossRef Medline

25. Lew SM, Kothbauer KF. Tethered cord syndrome: an updated review. Pediatr Neurosurg 2007;43:236-48 CrossRef Medline

26. Krings T, Geibprasert S, Luo CB, et al. Segmental neurovascular syndromes in children. Neuroimaging Clin N Am 2007;17:245-58 CrossRef Medline 